\title{
Five Personality Traits in Late-onset Depression in Hong Kong
}

\author{
JDW Chik, TK Poon, RMK Ng
}

\begin{abstract}
Objective: This study aimed to examine the association between five personality traits and late-onset depression in Hong Kong older people.

Methods: This cross-sectional study included a convenience sample of 40 older people with late-onset depression (LOD) and 54 non-depressed elderly controls. The patients were assessed using the NEO Five Factor Inventory (for personality), the Hamilton Depression Rating Scale (for depression severity), the Mini-Mental State Examination (for cognitive function), the Lawton Instrumental Activities of Daily Living (for functioning), and the Cumulative Illness Rating Scale (for number of physical illnesses).

Result: The LOD group had a higher Hamilton Depression Rating Scale score (18.9 vs 3.7, p < 0.001), lower Mini Mental State Examination score (24.9 vs 26.4, p = 0.004), and lower Instrumental Activities of Daily Living scale score (21.9 vs 23.7, p = 0.013). On the NEO Five Factor Inventory, the LOD group had a higher neuroticism score $(30.7$ vs $17.5, \mathrm{p}<0.001)$ and lower scores on extraversion $(19.0$ vs $26.4, \mathrm{p}<0.001)$, openness ( 18.9 vs $21.5, \mathrm{p}=0.026)$, and conscientiousness $(29.1$ vs $33.8, \mathrm{p}<0.001)$. Neuroticism was the only significant predictor of LOD (odds ratio $=2.325, \mathrm{p}=0.001$ ) and the only significant factor associated with depression severity $(\beta=0.581, \mathrm{p}=0.003)$.

Conclusions: The personality trait of neuroticism is associated with LOD and its severity. Assessment of personality traits should be included in the assessment of people with depression.
\end{abstract}

Key words: Depression; Personality

Janice Dan-Wai Chik, MBBS, MRCPsych, FHKCPsych, FHKAM (Psychiatry), Department of Psychiatry, Kowloon Hospital, Hong Kong

Ting-Keung Poon, MBBS, MRCPsych, FHKCPsych, FHKAM (Psychiatry), Department of Psychiatry, Kowloon Hospital, Hong Kong

Roger Man-Kin Ng, MBChB, FHKCPsych, FHKAM (Psychiatry), Department of Psychiatry, Kowloon Hospital, Hong Kong

Address for correspondence: $\mathrm{Dr}$ Janice Dan-Wai Chik, Department of Psychiatry, Kowloon Hospital, 147A Argyle Street, Kowloon, Hong Kong, People's Republic of China.Email: janice.chik@gmail.com

Submitted: 23 October 2017; Accepted: 25 June 2018

\section{Introduction}

Depression in late life is prevalent and is the most common cause of emotional suffering. Chronic and recurrent depression increases disability and healthcare costs. ${ }^{1} \mathrm{~A}$ deeper understanding of late-onset depression (LOD) is needed to identify prognostic factors and develop effective interventions and prevention programmes. ${ }^{2}$

Personality traits contribute to individual differences in cognitive, affective, and behavioural responses to environmental events ${ }^{3}$ and are distributed on a continuum. The Five Factor Model is a universally accepted framework to describe an individual's personality. ${ }^{4}$ In this model, personality comprises five broad domains: neuroticism (negative emotionality and sensitivity), extraversion (positive affectivity, optimism, and sociability), openness to experience (innovation, curiosity, and non-dogmatic attitudes), agreeableness (altruism, modesty, and compassion), and conscientiousness (motivation and responsibility). ${ }^{4}$

Most personality trait studies focus on young-onset depression. A large-scale meta-analysis reported that depressive disorder in adults is associated with higher levels of neuroticism and lower levels of extraversion and conscientiousness. ${ }^{5}$ Personality traits, particularly neuroticism, affect LOD. Higher neuroticism scores are associated with an increased risk of subsequent newonset depression, ${ }^{6-8}$ a negative clinical course, ${ }^{9-12}$ and recurrent episodes..$^{13}$ People with remittent LOD have higher neuroticism levels than healthy old-age controls. ${ }^{14}$ Neuroticism has been shown to be independently associated with depressive symptomatology, even after adjusting for increased physical illness and stressful life events. ${ }^{15,16}$ In addition, LOD is associated with lower levels of conscientiousness, ${ }^{8,10,17,18}$ extraversion, ${ }^{17,18}$ and openness. ${ }^{18}$ People with remittent LOD have been shown to have lower levels of extraversion than healthy controls had..$^{14,19}$

The association of personality traits with LOD in Hong Kong has never been studied. The present study aimed to examine the association between the five personality traits and the diagnosis and severity of depression in Chinese elderly people. Such findings can help improve clinical practice and guide future research directions. We hypothesised that (1) people with LOD differ from never- 
depressed older people in personality scores; (2) neuroticism is most correlated with LOD; (3) neuroticism levels are higher in people with LOD and positively correlated with symptom severity; and (4) people with LOD have lower extraversion and conscientiousness scores.

\section{Methods}

This cross-sectional case-control study was approved by our institutional ethical review board (KC/KE-15-0030/ER-3). All potential participants were informed of the purpose and procedures of the study and the right to refuse participation or withdraw from the study at any time. Informed written consent was obtained from each participant.

Between April 2015 and July 2016, a convenience sample of elderly people without dementia was recruited from both the psychiatric outpatient clinics and inpatient wards of Kowloon Hospital as cases. A sample of nondepressed elderly people without dementia or known history of mental illness was recruited from a healthcare centre as controls. People with LOD were defined as those with the first lifetime depressive episode at or after age 60 years. ${ }^{1}$ The exclusion criteria were (1) onset of depression before age 60 years, (2) Mini Mental State Examination score below the suggested cut-off, (3) a history of any other psychiatric disorders, (4) other major cognitive and neurological disorders, (5) terminal illness, (6) communication difficulties, and (7) total illiteracy. Assessments were made within 2 weeks of referral by psychiatrists.

The diagnosis of depression was based on the ICD-10 diagnostic criteria ${ }^{20}$ and entailed assessments by the attending psychiatrist, collateral information from family members, and a consensus diagnostic meeting with the senior consultant psycho-geriatrician. The severity of depression was measured using the 17-item Hamilton Depression Rating Scale, which has been validated in the Chinese population with satisfactory internal reliability (Cronbach's $\alpha=0.714$ ), excellent inter-rater reliability, and good item-total score correlations. ${ }^{21}$ Total scores range from 0 to 52, with higher scores indicating higher severity of depressive symptoms; a cut-off score of $\geq 10$ indicates depression. ${ }^{21}$ The Hamilton Depression Rating Scale score is strongly negatively correlated with the Global Assessment Scale score. ${ }^{21}$

Personality was assessed using the NEO Five Factor Inventory, ${ }^{4}$ which has been validated for use in the Chinese population, with a median internal consistency of 0.63 for all five personality factors. ${ }^{22}$ The inventory comprises 60 selfreport items (12 for each of the five personality factors) on a 5-point Likert Scale (from 'strongly disagree' to 'strongly agree'). Total scores for each personality factor range from 0 to 48 .

Cognitive function was assessed using the Mini Mental State Examination, which has good validity ( $r$ $=0.94$ ) and reliability (Cronbach's $\alpha=0.86$, test-retest reliability $=0.78$, and inter-rater reliability $=0.99) .{ }^{23}$ The maximum total score is 30 . The cut-off scores for local elderly people are $\leq 18$ for illiterate subjects, $\leq 20$ for those with 1 to 2 years of schooling, and $\leq 22$ for those with $>2$ years of schooling. ${ }^{24}$

Functioning was assessed using the Chinese version of the Instrumental Activities of Daily Living scale, which has good validity and reliability (Cronbach's $\alpha=0.86$, testretest reliability $=0.90$, and inter-rater reliability $=0.99) .{ }^{25}$ Nine items are rated on a four-point scale, with scores ranging from 0 to 27 and higher scores indicating better functioning.

The number of physical illnesses (from 14 organ domains, except for the psychiatric domain) was measured using the Cumulative Illness Rating Scale. The scale has inter-rater reliability of 0.78 for outpatients and 0.88 for inpatients. ${ }^{26}$

Data were analysed using SPSS (Windows version 23.0; IBM Corp, Armonk [NY], US). All statistical tests were two-tailed, with an alpha level of significance set at 0.05 . Categorical variables were compared using the Chi squared test or Fisher's exact test as appropriate. Continuous variables were compared using $t$-tests. Logistic regression analysis was used to identify significant personality factors associated with LOD. Linear regression analysis was used to assess the association of personality factors with severity of depression. Variables that were significant in univariate analyses were included as covariates. Stepwise regression methods were not performed owing to the small sample size. Sample size calculation was based on a study that reported a significantly higher NEO Five Factor Inventory neuroticism score in the depressed than the control group (39.05 \pm 7.00 vs $24.85 \pm 6.75) .{ }^{17}$ A sample of 40 participants in each group was needed to detect differences in neuroticism scores and to achieve $80 \%$ power at the $5 \%$ significance level.

\section{Results}

Of the 57 older adults with LOD screened, nine refused to participate, four did not meet the depression definition, and four were excluded because of psychotic symptoms $(n=1)$, significant shortness of breath during assessment $(n=1)$, Parkinson's disease $(n=1)$, and end-stage cancer $(n=1)$. Of the 66 non-depressed older adults screened, eight refused to participate and four were excluded because of known ICD-10 psychiatric illness. The final sample consisted of 40 LOD cases (27 women and 13 men) and 54 controls (35 women and 19 men).

The two groups were comparable in terms of age, gender, educational level ( $>70 \%$ of participants had primary or secondary school level education), and marital status ( $>50 \%$ of participants were married). Most participants did not have any religious beliefs (Table 1).

The LOD group had a higher Hamilton Depression Rating Scale score (18.9 vs 3.7, p < 0.001), lower Mini Mental State Examination score (24.9 vs 26.4, $\mathrm{p}=0.004)$, and lower Instrumental Activities of Daily Living scale score (21.9 vs 23.7, p = 0.013). On the NEO Five Factor Inventory, the LOD group had a higher neuroticism score 
Table 1. Demographic data of the late-onset depression and control groups.

\begin{tabular}{|c|c|c|c|c|c|}
\hline Variable & Late-onset depression $(n=40)^{*}$ & Control $(n=54)^{*}$ & $\mathbf{t} / \chi^{2}$ & df & p Value \\
\hline Age, $y$ & $72.0 \pm 6.9$ & $73.1 \pm 6.4$ & -0.77 & 92 & 0.44 \\
\hline Gender & & & 0.07 & 1 & 0.79 \\
\hline Male & $13(32.5)$ & $19(35.2)$ & & & \\
\hline Female & $27(67.5)$ & $35(64.8)$ & & & \\
\hline Education & & & 5.79 & 3 & 0.12 \\
\hline No formal education & $9(22.5)$ & $4(7.4)$ & & & \\
\hline Primary & $15(37.5)$ & $18(33.3)$ & & & \\
\hline Secondary & $13(32.5)$ & $23(42.6)$ & & & \\
\hline Tertiary & $3(7.5)$ & $9(16.7)$ & & & \\
\hline Marital status & & & 3.17 & 3 & 0.37 \\
\hline Single & $4(10.0)$ & $2(3.7)$ & & & \\
\hline Married & $22(55.0)$ & $38(70.4)$ & & & \\
\hline Separated/divorced & $4(10.0)$ & $3(5.5)$ & & & \\
\hline Widowed & $10(25.0)$ & $11(20.4)$ & & & \\
\hline Religion & & & 0.52 & 1 & 0.47 \\
\hline Yes & $17(42.5)$ & $19(35.2)$ & & & \\
\hline No & $23(57.5)$ & $35(64.8)$ & & & \\
\hline
\end{tabular}

Data are presented as mean \pm standard deviation or No. (\%) of participants

Table 2. Clinical data of the late-onset depression and control groups.

\begin{tabular}{|lcccc|}
\hline Variable & $\begin{array}{c}\text { Late-onset } \\
\text { depression }(\mathbf{n = 4 0})^{*}\end{array}$ & $\begin{array}{c}\text { Control } \\
(\mathbf{n = 5 4})^{*}\end{array}$ & t & p Value \\
Hamilton Depression Rating Scale & $18.9 \pm 5.2$ & $3.7 \pm 1.8$ & 17.71 & $<0.001$ \\
\hline Mini-Mental State Examination & $24.9 \pm 2.3$ & $26.4 \pm 2.5$ & -2.94 & 0.004 \\
\hline Lawton Instrumental Activities of Daily Living & $21.9 \pm 3.9$ & $23.7 \pm 3.0$ & -2.54 & 0.013 \\
\hline Cumulative Illness Rating Scale & $3.4 \pm 1.6$ & $3.2 \pm 1.6$ & 0.73 & 0.443 \\
\hline NEO Five Factor Inventory & & & & \\
$\quad$ Neuroticism & $30.7 \pm 4.7$ & $17.5 \pm 5.9$ & 11.72 & $<0.001$ \\
$\quad$ Extraversion & $19.0 \pm 5.6$ & $26.4 \pm 5.2$ & -6.64 & $<0.001$ \\
Openness & $18.9 \pm 5.6$ & $21.5 \pm 5.5$ & -2.26 & 0.026 \\
$\quad$ Agreeableness & $30.1 \pm 4.7$ & $30.8 \pm 5.1$ & -0.70 & 0.486 \\
Conscientiousness & $29.1 \pm 5.0$ & $33.8 \pm 5.7$ & -4.15 & $<0.001$ \\
\hline
\end{tabular}

Data are presented as mean \pm standard deviation

(30.7 vs $17.5, \mathrm{p}<0.001)$ and lower scores on extraversion (19.0 vs $26.4, \mathrm{p}<0.001$ ), openness ( 18.9 vs $21.5, \mathrm{p}=0.026$ ), and conscientiousness $(29.1$ vs $33.8, \mathrm{p}<0.001)$ [Table 2].

In the logistic regression model, neuroticism was the only significant predictor of LOD (odds ratio $=2.325, \mathrm{p}=$ 0.001 , Table 3). In the linear regression model, neuroticism was the only significant factor associated with depression severity $(\beta=0.581, \mathrm{p}=0.003$, Table 4$)$.

\section{Discussion}

In line with our hypothesis, LOD was associated with higher neuroticism score and lower scores on extraversion, conscientiousness, and openness. Neuroticism was the only personality factor that was predictive of LOD and associated with depression severity. However, these findings are typical of a depressive state of mind, as neuroticism is characterised by negative emotionality, low extraversion is characterised by social withdrawal and a reduction in positive affect, and low conscientiousness is characterised by inefficiency and decreased motivation. The direction of causality could not be inferred owing to the cross-sectional design, but various explanations have been proposed. Personality can influence the onset of depression 
Table 3. Logistic regression analysis for predictors of late-onset depression $(n=94)$.

\begin{tabular}{|lccc|}
\hline Variable & B & $\begin{array}{c}\text { Odds ratio }(\mathbf{9 5 \%} \\
\text { confidence interval) }\end{array}$ & p Value \\
Mini Mental State Examination & -0.597 & $0.551(0.296-1.025)$ & 0.060 \\
\hline Lawton Instrumental Activities of Daily Living & 0.142 & $1.153(0.787-1.689)$ & 0.465 \\
\hline Cumulative Illness Rating Scale & 0.949 & $2.583(0.992-6.728)$ & 0.052 \\
\hline NEO Five Factor Inventory & & & \\
$\quad$ Neuroticism & 0.844 & $2.325(1.405-3.845)$ & 0.001 \\
Extraversion & -0.233 & $0.792(0.619-1.013)$ & 0.063 \\
Openness & 0.022 & $1.022(0.775-1.346)$ & 0.878 \\
Agreeableness & 0.258 & $1.294(0.927-1.808)$ & 0.130 \\
Conscientiousness & 0.335 & $1.398(0.925-2.111)$ & 0.112 \\
\hline
\end{tabular}

Table 4. Linear regression analysis for association with the severity of late-onset depression $(n=40)$.

\begin{tabular}{|lcccc|}
\hline Variable & $\mathbf{t}$ & $\boldsymbol{\beta}$ & $\mathbf{B}$ (95\% CI) & p Value \\
Mini Mental State Examination & -1.293 & -0.268 & $-0.608(-1.567$ to 0.351$)$ & 0.206 \\
\hline Lawton Instrumental Activities of Daily Living & -0.194 & -0.033 & $-0.044(-0.512$ to 0.423$)$ & 0.847 \\
\hline Cumulative Illness Rating Scale & -0.850 & -0.154 & $-0.508(-1.727$ to 0.711$)$ & 0.402 \\
\hline NEO Five Factor Inventory & & & & \\
$\quad$ Neuroticism & 3.257 & 0.581 & $0.648(0.242$ to 1.053$)$ & 0.003 \\
$\quad$ Extraversion & 1.368 & 0.229 & $0.215(-0.105$ to 0.535$)$ & 0.181 \\
$\quad$ Openness & 0.158 & 0.034 & $0.031(-0.373$ to 0.436$)$ & 0.875 \\
$\quad$ Agreeableness & 0.038 & 0.006 & $0.007(-0.361$ to 0.374$)$ & 0.970 \\
$\quad$ Conscientiousness & 1.390 & 0.233 & $0.241(-0.113$ to 0.596$)$ & 0.175 \\
\hline
\end{tabular}

(vulnerability model) and how depression is expressed and experienced (pathoplasty model). Likewise, depression can cause transient changes to the personality (complication model) or even cause enduring damage to the personality after a depressive episode (scar model). ${ }^{27,28}$ Personality, especially neuroticism, and depression have substantial shared genetic roots and a conceptual overlap (the genetic spectrum model). ${ }^{29-31}$ However, the degree of genetic overlap remains controversial, and further longitudinal and genetic research are necessary.

Neuroticism has been shown to affect stress-coping styles (appraisal of an event as stressful and the likelihood of maladaptive coping strategies) and lead to a higher chance of depressive symptoms. ${ }^{32-35}$ Elderly people may experience more stress because of decline in physical illness and mental capacity, changes in role, loss of loved ones, and social isolation. Pre-existing neuroticism may aggravate these vulnerabilities and make elderly people more prone to depression..$^{16}$ In addition, subjective social support is also a significant contributor to depression severity in those with high neuroticism levels. ${ }^{36,37}$

People scoring low on extraversion are typically more withdrawn and reserved and do not actively seek advice and support in times of perceived stress and difficulty. ${ }^{33}$ Low extraversion together with impeded social networks and decline in pleasurable activities may increase vulnerability to depressive symptoms. ${ }^{16}$

People with low conscientiousness tend to be careless, disorganised, and inefficient. ${ }^{4}$ They have inefficient task performance and hence increased levels of minor failures and stressors. Conscientious people with well-defined goals may have a sense of self-discipline, which translates to healthier lifestyle and less health-damaging behaviours. ${ }^{38}$ The potentially pathogenic behaviours associated with low conscientiousness may catalyse disease or long-lasting injury in earlier phases of life and thereby contribute to overall morbidity in old age. ${ }^{38}$ In elderly people, lower conscientiousness may be associated with higher medical burden, which in turn may contribute to depression..$^{38}$ The lack of planning and organisation may make elderly people unmotivated to remove the detrimental stressor and situation when depressed. ${ }^{4,34,35}$

Individuals with lower openness scores tend to be conservative in their beliefs and have restricted cognitive flexibility. ${ }^{4}$ They may not be flexible and accepting toward their daily mood fluctuations, with a tendency toward 
distress and depressive symptoms. ${ }^{18}$ Greater openness is associated with greater awareness of future care needs and information gathering in older adults. ${ }^{39}$ Those with lower openness may have impeded problem solving and hence less positive attitudes and reduced likelihood of effective planning and exploration of different possibilities in times of low mood and stress.

Agreeableness describes people who are altruistic, trusting, sympathetic, and desirous of social acceptability and harmony. ${ }^{4}$ In the present study, agreeableness scores did not differ between patients with LOD and controls. This may be because older Chinese people are influenced by Confucian thoughts, which promote forbearance and value interpersonal relationships, interdependent family relationships, and filial responsibility. Harmony is the system's principle for interpersonal relationships, ${ }^{40}$ and Confucianism holds that individuals should act courteously irrespective of mood states. This trait may thus be mediated by other factors and not directly related to mood states. Assessment of agreeableness may be useful in determining the successfulness of psychotherapy in patients with LOD. ${ }^{41}$

\section{Limitations}

The cross-sectional design of this study provides no information about the causal relationship between personality and depression. Prospective longitudinal studies on the patterns of personality change (from before the onset of depression to the acute depressive phase and after receiving treatment) are necessary. The small sample size may not have adequate power to detect personality differences between the two groups. Larger studies are necessary to verify our findings. Self-rated instruments may have resulted in reporting bias owing to perceived social desirability, positive self-portrayal, and influences by the current mood state (state-trait issue). Exclusion of illiterate people may have resulted in selection bias and under-representation of such people, but such exclusion was necessary because the NEO Five Factor Inventory is a self-rated tool. Those who were severely ill were likely not referred, and thus, the most-depressed patients may have been excluded. Those with mild depression in the community were also not recruited, and thus, the results are not generalisable to this population. Controls who volunteered to participate may be extroverted, and hence, they may present with above-average cheerfulness and optimism.

\section{Clinical Implications}

Personality traits are often neglected in the diagnosis and management of depression. However, traits are useful in case formulation, treatment planning, determining the treatment outcome, and primary prevention (by identifying those at risk). ${ }^{5}$ It is clinically relevant to determine whether early intervention for persons high in neuroticism (and perhaps low in extraversion, conscientiousness, and openness) can effectively prevent the onset of full-blown depression or future recurrent episodes. Evidence and practical guidelines about optimal treatment for a particular or combinations of personality traits remain scarce. Psychological therapies may increase the effectiveness of pharmacological therapies. Nonetheless, the aetiology of depression is multifactorial and encompasses interactions between biological, psychological, and social vulnerabilities. Possible buffering factors such as social support and coping style are important attributes of the aetiology of depression that were not incorporated into the current study. Innate personality traits may be exacerbated by ageing, adversity, or other life events and may turn a once-benign personality trait into a mental illness like depression. Cerebrovascular risk factors also play important roles in LOD. ${ }^{42,43}$ The mediators and moderators that act between personality traits and LOD remain mostly unknown. Longitudinal studies with large sample sizes are necessary to determine such associations.

\section{Conclusion}

The personality trait of neuroticism is associated with LOD and its severity. The assessment of personality traits enables deeper understanding of the patient, rapport building, and customisation of the treatment plan for an optimal outcome.

\section{Acknowledgements}

The authors would like to thank Dr Law Tung Chi, Dr Catherine Chen, and the Kowloon Hospital Psychogeriatric team and nursing staff for facilitating the recruitment of participants.

\section{Declaration}

No sponsorship or grant was received. The authors have no conflicts of interest to disclose.

\section{References}

1. Blazer DG. Depression in late life: review and commentary. J Gerontol A Biol Sci Med Sci 2003;58:249-65. Crossref

2. Smit F, Ederveen A, Cuijpers P, Deeg D, Beekman A. Opportunities for cost-effective prevention of late-life depression: an epidemiological approach. Arch Gen Psychiatry 2006;63:290-6. Crossref

3. Clark LA. Temperament as a unifying basis for personality and psychopathology. J Abnorm Psychol 2005;114:505-21. Crossref

4. Costa PT, McCrae RR. Revised NEO Personality Inventory (NEOPIR) and NEO Five Factor Inventory (NEO-FFI) Professional Manual. Florida: Psychological Assessment Resources; 1992.

5. Kotov R, Gamez W, Schmidt F, Watson D. Linking "big" personality traits to anxiety, depressive, and substance use disorders: a metaanalysis. Psychol Bull 2010;136:768-821. Crossref

6. Duberstein PR, Pálsson SP, Waern M, Skoog I. Personality and risk for depression in a birth cohort of 70-year-olds followed for 15 years. Psychol Med 2008;38:663-71. Crossref

7. Steunenberg B, Beekman AT, Deeg DJ, Kerkhof AJ. Personality and the onset of depression in late life. J Affect Disord 2006;92:24351. Crossref

8. Weiss A, Sutin AR, Duberstein PR, Friedman B, Bagby RM, Costa PT Jr. The personality domains and styles of the five-factor model are related to incident depression in Medicare recipients aged 65 to 100 . Am J Geriatr Psychiatry 2009;17:591-601. Crossref 
9. Canuto A, Giannakopoulos P, Meiler-Mititelu C, Delaloye C, Herrmann FR, Weber K. Personality traits influence clinical outcome in day hospital-treated elderly depressed patients. Am J Geriatr Psychiatry 2009;17:335-43. Crossref

10. Hayward RD, Taylor WD, Smoski MJ, Steffens DC, Payne ME. Association of five-factor model personality domains and facets with presence, onset, and treatment outcomes of major depression in older adults. Am J Geriatr Psychiatry 2013;21:88-96. Crossref

11. Steffens DC, McQuoid DR, Smoski MJ, Potter GG. Clinical outcomes of older depressed patients with and without comorbid neuroticism. Int Psychogeriatr 2013;25:1985-90. Crossref

12. Steunenberg B, Beekman AT, Deeg DJ, Bremmer MA, Kerkhof AJ. Mastery and neuroticism predict recovery of depression in later life. Am J Geriatr Psychiatry 2007;15:234-42. Crossref

13. Steunenberg B, Braam AW, Beekman AT, Deeg DJ, Kerkhof AJ. Evidence for an association of the big five personality factors with recurrence of depressive symptoms in later life. Int J Geriatr Psychiatry 2009;24:1470-7. Crossref

14. Weber K, Giannakopoulos P, Delaloye C, de Bilbao F, Moy G, Moussa A, et al. Volumetric MRI changes, cognition and personality traits in old age depression. J Affect Disord 2010;124:275-82. Crossref

15. Lyness JM, Duberstein PR, King DA, Cox C, Caine ED. Medical illness burden, trait neuroticism, and depression in older primary care patients. Am J Psychiatry 1998;155:969-71. Crossref

16. Ormel J, Oldehinkel AJ, Brilman EI. The interplay and etiological continuity of neuroticism, difficulties, and life events in the etiology of major and subsyndromal, first and recurrent depressive episodes in later life. Am J Psychiatry 2001;158:885-91. Crossref

17. Koorevaar AM, Comijs HC, Dhondt AD, van Marwijk HW, van der Mast RC, Naarding P, et al. Big Five personality and depression diagnosis, severity and age of onset in older adults. J Affect Disord 2013;151:178-85. Crossref

18. Weber K, Giannakopoulos P, Bacchetta JP, Quast S, Herrmann FR, Delaloye $\mathrm{C}$, et al. Personality traits are associated with acute major depression across the age spectrum. Aging Ment Health 2012;16:47280. Crossref

19. Canuto A, Giannakopoulos P, Moy G, Rubio MM, Ebbing K, MeilerMititelu C, et al. Neurocognitive deficits and personality traits among euthymic patients with mood disorders in late life. J Neurol Sci 2010;299:24-9. Crossref

20. World Health Organization. The ICD-10 classification of mental and behavioral disorders: clinical descriptions and diagnostic guidelines. Geneva: World Health Organization; 1992.

21. Zheng YP, Zhao JP, Phillips M, Liu JB, Cai MF, Sun SQ, et al. Validity and reliability of the Chinese Hamilton Depression Rating Scale. Br J Psychiatry 1988;152:660-4. Crossref

22. Yang J, McCrae RR, Costa PT Jr, Dai X, Yao S, Cai T, et al. Crosscultural personality assessment in psychiatric populations: The NEOPI-R in the People's Republic of China. Psychol Assess 1999;11:35968. Crossref

23. Chiu HF, Lee HC, Chung WS, Kwong PK. Reliability and validity of the Cantonese version of Mini-Mental State Examination: a preliminary study. J Hong Kong Coll Psychiatry 1994;4:25-8.

24. Chiu HF, Lam LC, Chi I, Leung T, Li SW, Law WT, et al. Prevalence of dementia in Chinese elderly in Hong Kong. Neurology 1998;50:10029. Crossref

25. Tong AY, Man DW. The validation of the Hong Kong Chinese version of the Lawton Instrumental Activities of Daily Living Scale for institutionalized elderly persons. OTJR (Thorofare N J) 2002;22:13242. Crossref

26. Miller MD, Paradis CF, Houck PR, Mazumdar S, Stack JA, Rifai AH, et al. Rating chronic medical illness burden in geropsychiatric practice and research: application of the Cumulative Illness Rating Scale. Psychiatry Res 1992;41:237-48. Crossref

27. Clark LA, Watson D, Mineka S. Temperament, personality, and the mood and anxiety disorders. J Abnorm Psychol 1994;103:10316. Crossref

28. Klein DN, Kotov R, Bufferd SJ. Personality and depression: explanatory models and review of the evidence. Annu Rev Clin Psychol 2011;7:269-95. Crossref

29. Hettema JM, Neale MC, Myers JM, Prescott CA, Kendler KS. A population-based twin study of the relationship between neuroticism and internalizing disorders. Am J Psychiatry 2006;163:85764. Crossref

30. Kendler KS, Neale MC, Kessler RC, Heath AC, Eaves LJ. A longitudinal twin study of personality and major depression in women. Arch Gen Psychiatry 1993;50:853-62. Crossref

31. Kendler KS, Myers J. The genetic and environmental relationship between major depression and the five-factor model of personality. Psychol Med 2010;40:801-6. Crossref

32. Gunthert KC, Cohen LH, Armeli S. The role of neuroticism in daily stress and coping. J Pers Soc Psychol 1999;77:1087-100. Crossref

33. David JP, Suls J. Coping efforts in daily life: role of big five traits and problem appraisals. J Pers 1999;67:265-94. Crossref

34. O'Brien TB, DeLongis A. The interactional context of problem, emotion-, and relationship-focused coping: the role of the big five personality factors. J Pers 1996;64:775-813. Crossref

35. Watson D, Hubbard B. Adaptational style and dispositional structure: coping in the context of the five-factor model. J Pers 1996;64:73774. Crossref

36. Oddone CG, Hybels CF, McQuoid DR, Steffens DC. Social support modifies the relationship between personality and depressive symptoms in older adults. Am J Geriatr Psychiatry 2011;19:123-31. Crossref

37. Sarason BR, Shearin EN, Pierce GR, Sarason IG. Interrelations of social support measures: theoretical and practical implications. J Pers Soc Psychol 1987;52:813-32. Crossref

38. Chapman BP, Lyness JM, Duberstein P. Personality and medical illness burden among older adults in primary care. Psychosom Med 2007;69:277-82. Crossref

39. Sörensen S, Duberstein PR, Chapman B, Lyness JM, Pinquart M. How are personality traits related to preparation for future care needs in older adults? J Gerontol B Psychol Sci Soc Sci 2008;63:P328-36. Crossref

40. Cheung FM, Leung K, Zhang JX, Sun HF, Gan YQ, Song WZ, et al. Indigenous Chinese personality constructs: is the Five-Factor Model complete? J Cross Cult Psychol 2001;32:407-33. Crossref

41. Canuto A, Meiler-Mititelu C, Herrmann F, Giannakopoulos P, Weber K. Impact of personality on termination of short-term group psychotherapy in depressed elderly outpatients. Int J Geriatr Psychiatry 2008;23:22-6. Crossref

42. Alexopoulos GS, Meyers BS, Young RC, Campbell S, Silbersweig D, Charlson M. 'Vascular depression' hypothesis. Arch Gen Psychiatry 1997;54:915-22. Crossref

43. Thomas AJ, O'Brien JT, Davis S, Ballard C, Barber R, Kalaria $\mathrm{RN}$, et al. Ischemic basis for deep white matter hyperintensities in major depression: a neuropathological study. Arch Gen Psychiatry 2002;59:785-92. Crossref 